on the Internet]. 2007;13(7). Disponible en http// www. cdc.gov/EID/content/1317/1081/htm.)

\section{Fuerte asociación entre el sexo bucogenital y el cáncer faríngeo}

Las personas que durante su vida hayan tenido sexo bucogenital con seis o más parejas tienen muchas más probabilidades de sufrir cáncer faríngeo que otras, sea cual fuere su historia en cuanto al uso de alcohol y tabaco. A esta conclusión llegaron investigadores afiliados a la Escuela de Salud Pública de Johns Hopkins que realizaron un estudio de casos y testigos en el que participaron 100 pacientes recién diagnosticados de cáncer faríngeo - en las amígdalas, base de la lengua y garganta-, y 200 pacientes sin cáncer como testigos. Teniendo en cuenta el trabajo anterior de otros investigadores, el grupo de Johns Hopkins se propuso evaluar la posible relación entre la infección por el papilomavirus humano $(\mathrm{PVH})$ y el carcinoma escamoso de faringe. Se recolectó sangre y saliva de la garganta de los participantes y al combinarlas con moléculas de anticuerpos se pudo determinar si la persona había tenido alguna infección por PVH. Todos completaron una autoentrevista que reveló información sobre su experiencia sexual, incluso el número de personas con quienes habían practicado el sexo bucogenital, así como hábitos de higiene bucal, historial médico, cáncer en la familia, y uso de marihuana, alcohol y tabaco.

Los resultados fueron concluyentes. Haber tenido sexo vaginal con un alto número de parejas ( 26 o más) se asoció con el cáncer estudiado (oportunidad relativa u odds ratio: 3,1; IC95\%: 1,5-6,5), lo mismo que haber tenido sexo bucogenital con 6 o más parejas (OR: 3,4; IC95\%: 1,3-8,8). El grado de asociación aumentó con el número de parejas. El cáncer faríngeo también resultó asociado con la infección bucal por el PVH-16 (OR: 14,6; IC95\%: 6,3$36,6)$, con infecciones bucales por cualquiera de 37 tipos de PVH (OR: 12,3; IC95\%: 5,4-26,4), y con seropositividad a la proteína de la cápside L1 del PVH-16 (OR:32,2; CI95\%: 14,6-71,3). El ADN de PVH-16 se detectó en $72 \%$ de 100 especímenes de tumor preparados en cortes de parafina (IC95\%: 6281) y $64 \%$ de los pacientes con cáncer resultaron seropositivos a la oncoproteína E6 o la E7 o ambas del VPH-16. La seropositividad a la L1 del PVH-16 se asoció con cáncer faríngeo en participantes con antecedentes de un fuerte uso de tabaco y alcohol (OR; 19,4; IC95\%: 3,3-113,9) y entre otros sin esos antecedentes (OR;33,6; IC95\% 13,3-84,8). La relación aumentó también en los pacientes con infección bucal por VIH-16, sea cual fuere su uso de alcohol y tabaco. Por contraste, ese uso aumentó la relación con el cáncer faríngeo principalmente entre los pacientes no expuestos a PVH-16.

Aunque no puede descartarse la transmisión del virus de boca a boca $u$ otra forma desconocida, los resultados de este estudio tienen gran importancia para la salud pública. Desde 1973, en los Estados Unidos ha aumentado la incidencia anual del cáncer de las amígdalas y base de la lengua. La extensa práctica del sexo bucogenital entre los adolescentes puede haber contribuido a ese aumento. De todos modos, es necesario añadir esa práctica sexual a la lista de causas del cáncer de garganta. Además, los datos obtenidos deben alentar al uso de condones durante el sexo bucogenital.

Por otra parte, estos resultados muestran claramente una poderosa razón para que la nueva vacuna Gardasil contra el PVH se administre no solo a las adolescentes, sino también a los varones de esa edad. Cuando en 2006 se aprobó el uso de dicha vacuna, solamente se consideraron las cepas más peligrosas del PVH causantes del cáncer cervicouterino. Por eso la vacuna no se ha recomendado para los varones.

Hasta ahora no ha habido ningún estudio sobre la eficacia de la vacuna para prevenir el cáncer bucofaríngeo. Si la nueva vacuna contra el PVH resultara tan eficaz en la prevención del cáncer bucofaríngeo en ambos sexos como lo es del cáncer cervicouterino, se comprobaría sin lugar a dudas la causalidad entre esa práctica sexual y el cáncer de la lengua y garganta y se buscarían los medios para reconocer a quienes están en riesgo. (D'Souza G, et al. Case-control study of human papillomavirus and oropharyngeal cancer. N Engl J Med. 2007;356: 1944-56.)

\section{Las enfermedades emergentes y los pobres del mundo en desarrollo}

De todas las aflicciones de salud, las enfermedades respiratorias y diarreicas, la tuberculosis y el paludismo tienen el impacto más grande en los pobres del mundo. Sin embargo, en los países de bajos y medianos ingresos, durante los últimos 10 años se ha logrado una disminución notable de las muertes debidas a enfermedades transmisibles. Si esta tendencia continúa, como se espera, la comunidad internacional de salud pública tendrá que concentrar su atención en otros riesgos. En un artículo reciente se expone la hipótesis de que, junto con los avances en el tratamiento de las enfermedades transmisibles, las características del futuro crecimiento de las ciudades determinarán qué problemas de salud ocuparán los 10 lugares más importantes. Hay riesgos emergentes que ya se incluyen entre los de mayor peso por el número de muertes que produ- 
cen. Además, se relacionan con los rasgos del crecimiento futuro de las ciudades: disminución de la densidad, velocidad de la urbanización, pobreza, formación de barrios pobres y envejecimiento de la población.

Si bien las enfermedades transmisibles y el VIH/sida en particular continuarán asolando a los pobres, hay cuatro riesgos que aumentarán en importancia: la violencia, los accidentes de circulación, la obesidad y los asentamientos en lugares inseguros, donde tienden a congregarse los pobres y donde acechan a la población peligros y desastres naturales. Para el 2030, casi 2000 millones de personas vivirán en tugurios que representan un enorme peligro por su fragilidad y propensión al fuego. En consecuencia, los organismos de salud pública tendrán que ajustarse a los factores específicos del país y la región para hacer frente al cambiante perfil de riesgo.

En los países en desarrollo, la expansión urbana descontrolada hacia la periferia de las ciudades dificultará aun más el acceso a la atención de salud. El aumento del número de vehículos de motor en medio de una infraestructura inadecuada intensificará la contaminación del aire y la frecuencia de accidentes. Existirá el dilema de que las poblaciones urbanas pobres sigan sufriendo de desnutrición junto a los riesgos de salud planteados por la obesidad. Además, se espera un gran incremento de barrios pobres donde es probable que la violencia y el homicidio se añadan a la carga de dificultades. Se ha señalado que los factores asociados con la violencia incluyen un gran segmento de jóvenes sin empleo, pero con una conciencia creciente de las desigualdades socioeconómicas, el deseo de identidad y pertenencia, por ejemplo, en una pandilla y una historia anterior de conflicto.

En los dos gigantes asiáticos India y China, que tienen la mayor parte de los habitantes del pla- neta y $40 \%$ de la población urbana, se multiplicarán las ciudades más grandes y el crecimiento económico continuará acelerándose. Sin embargo en África, al contrario de lo que ha ocurrido en América Latina y los países asiáticos, las ciudades muestran un crecimiento desbocado sin previos adelantos en el sector industrial.

Más de 70 países se están descentralizando y pasando los poderes de financiamiento y decisión a los gobiernos locales. Casi 25 naciones latinoamericanas lograron ese cambio en el decenio de 1990. En este sentido, el problema es que los encargados de tomar decisiones a nivel local suelen ser elegidos por voto popular y tener poca experiencia o adiestramiento en salud pública.

Este análisis sugiere que cuatro factores - los niveles de pobreza, la velocidad del crecimiento de las ciudades, la expansión descontrolada y el grado de descentralización- serán de mucha importancia en la configuración de nuevas estrategias sanitarias. Estas tendrán que diferenciarse según la región, ya que los cuatro factores varían en ritmo e intensidad en distintos lugares del mundo. Se requiere prestar más atención al bienestar físico de los pobres, quienes tienen que ser el foco de atención y prioridad al asignar recursos. Asimismo hay que reconocer que los avances que han permitido reducir las enfermedades infecciosas no pueden transferirse totalmente a las no transmisibles y lesiones del futuro. También hay que tener en cuenta que las intervenciones requerirán cada vez más la actuación de personas de campos distintos al de la salud pública. Por último, las ciudades pueden aprender unas de otras y la resultante cooperación horizontal será otro nuevo campo de asistencia para el desarrollo. (Campbell T, Campbell A. Emerging disease burdens and the poor in cities of the developing world. J Urban Health. 2007;84(Suppl 1):54-64.) 